\title{
Editorial: Supporting staff through change
}

\author{
Cathy Malone \\ Middlesex University London
}

Staff development teams routinely focus on supporting others to innovate and collaborate to improve learning and teaching, examining what can be done to facilitate reflection and present staff development in ways that reach across the whole campus. During the pandemic these teams were tasked with the challenge of rapid technical upskilling of both themselves and teams they worked with, as large staff groups used to high levels of face to face contact moved their courses online. At the same time there was a need to maintain quality of provision in terms of maintaining a high degree of interactivity in order to create an engaging student experience. Many of the usual challenges of staff development were writ large by the pandemic: there was an urgent need to undertake professional development, learn rapidly how to teach in an online environment when staff themselves were time poor and under pressure from the myriad of additional pandemic demands that home working brought with it, particularly for women employed in HE (Kovarovic et al., 2021). While many challenges felt familiar, the experience of the pandemic for many authors brought with it a dramatic increase in engagement and appetite for all forms of CPD. As many of the papers here attest, our colleagues were hungry for development in spite of the increased demands on their time.

The situation we confronted as a sector demanded innovative responses from large diverse staff groups. In these papers authors unpick precisely what is required to support and develop the cognitive and social capacity to collaborate in the pandemic. They also identify the components and prerequisites for innovation in terms of technical competence, feelings of autonomy and relatedness that together contribute to motivation to innovate (Averill and Major, 2020). Regarding technical upskilling, several authors stress the importance of avoiding the exclusive focus on operational and technical matters and the importance of acknowledging the scale of the paradigm shift that the sector experienced in moving wholesale online. 
Many staff teams and authors returned to the work of Wenger (1999) and revisited Communities of Practice (COP) as vehicles for staff development, and we see how this concept is refreshed and developed with some creativity adapted for an online pandemic context. The core features of academic communities of practice remained as spaces where 'academics can engage in discussions of informal and situated leaning to share experiences of what worked and what didn't' (Anderson, 2020, p.461). What was new was adapting to create these spaces in an online context. In this collection of papers we see development teams establish with some ingenuity online spaces and opportunities for sharing and collaboration at the level of online networks, developing radio shows, blogs, informal cafes and drop ins, workshops organised to support individual and peer reflection. This collection also provides detailed accounts from teams themselves engaged in their own journeys of shared structured reflection and autonomous development, confronting what worked and what didn't.

Read together these papers demonstrate the resilience of staff, and the capacity of teams to work together engaging in sustained critical reflection to both 'embrace the reset' (Robinson 2020) and face these challenges with considerable resources of ingenuity and creativity.

\section{References:}

Anderson, V. (2020) 'A digital pedagogy pivot: re-thinking higher education practice from an HRD perspective', Human Resource Development International, 23:4, 452-467, https://doi.org/10.1080/13678868.2020.1778999.

Averill, R., and Major, J. (2020) 'What motivates higher education educators to innovate? Exploring competence, autonomy, and relatedness - and connections with wellbeing', Educational Research, 62:2, 146-161, https://doi.org/10.1080/00131881.2020.1755877.

Kovarovic, K., Dixon, M., Hall, K., and Westmarland, N. (2021) 'The impact of Covid-19 on mothers working in UK Higher Education Institutions', Report for Research England 
https://www.dur.ac.uk/resources/lets.network/MothersinHEandCovid-

19ReportbyMAMSNetworkJune2021.pdf (Accessed 22 October 2021).

Robinson, S. (2020) 'A global reset of education', Prospects 49,7-9, https://doi.org/10.1007/s11125-020-09493-y.

Wenger, E. (1999) Communities of Practice: learning, meaning, identity. Cambridge, CUP. 